\title{
Managing transitions for sustainable development
}

\section{Book Chapter in: Understanding Industrial Transformation. Views from different disciplines. X. Olshoorn, Wieczorek, A. J. Dordrecht, Springer, 2006}

\section{Derk Loorbach and J an Rotmans}

\begin{abstract}
:
The challenge of sustainable development presents our society with the need for longterm, structural changes or transitions in sectors such as energy-supply, mobility, agriculture and health-care. Based on a multi-phase and multi-level framework for transitions, we ask whether managing transitions is possible and then outline an operational method for transition management.
\end{abstract}

Key words: transitions, transition management and sustainable development

\section{Introduction}

Our society is increasingly facing persistent problems, which cannot be solved by current policies based on traditional approaches alone. Too often current policies lead to sub-optimal solutions, generating even more persistent and complex problems in the long-term. Examples of these problems can be found in many European sectors: the agricultural sector with its many symptoms of unsustainability, visible in diseases like $\mathrm{BSE}^{1}$ and Foot $\&$ Mouth; the water sector with symptoms like floods, droughts and water quality problems; the energy sector with its one-sided and environmentally-detrimental energy supply system; the transport system with its concomitant air pollution and congestion; and the health care system with its exorbitant costs and waiting lists in the face of an ageing of the population. These persistent problems are complex, unstructured, involve many stakeholders, are surrounded by fundamental uncertainties, and are deeply rooted in our societal structures and institutions (Dirven et al., 2002). Their resolution demands a revision of both development processes and the institutions that have been built to handle them.

In order to resolve persistent societal problems structural transformations or transitions are necessary. In general terms, a transition can be portrayed as a longterm process of change during which a society or a subsystem of society fundamentally changes (Rotmans et al., 2000, Rotmans et al. 2001). Transitions require system innovations: organisation-exceeding, qualitative innovations, which are realised by a variety of participants within the system and which fundamentally change both the structure of the system and the relation between the participants. It is within these system innovations that innovations at the individual level occur, in

1 Bovine Spongiform Encephalopathy (BSE) or mad cow disease. 
terms of product, process and project innovations (Weaver et al, 2000). An example is a possible future energy transition to biomass, which will involve system innovations in transport (biofuels), electricity generation (co-combustion, gasification of biomass), agriculture (biocrops), but also in policy (integral biomass policy regarding energy, biodiversity, space use, agriculture and transport) and culture (surmount barriers among the public against alternative energy carriers).

The relation between transitions and system innovations on the one hand and sustainable development on the other hand is ambiguous (Kemp and Rotmans, 2001). Many transitions and system innovations that happened in the past were not set in motion based on a preconceived goal and did not lead to a more sustainable society. On the contrary, the detrimental environmental impact of technological innovations often outweighed the positive impacts of an efficiency increase. The fact that we are currently faced with the need to innovate and structurally change a number of societal systems is a tremendous challenge: to initiate transitions and system innovations from the preconceived goal of sustainable development. Because sustainable development is intrinsically a normative, ambiguous and subjective notion, a practical implementation of sustainable development has to incorporate the inherent conflicts between the values, ambitions and goals of a multitude of stakeholders.

\section{Scientific perspective}

Within the Dutch Knowledge network on System Innovations and Transitions (KSI) ${ }^{2}$ an inter- and transdisciplinary science perspective has been developed, represented in an overall research programme on transitions and system innovations (Rotmans et al., 2003). This new science perspective is based on a set of shared concepts, and aims to develop a deeper and broader knowledge base for transitions and system innovations. As Berkhout et al. (2003) argue, we need a thicker, context enriched understanding of transitions.

The first shared concept is that of transition itself. From an integrated systems perspective we define the concept of a transition as a shift in a system from one dynamic equilibrium to another equilibrium. The process of change in transitions is highly nonlinear: slow change is followed by rapid

A transition
... is the shift from an initial dynamic
equilibrium to a new dynamic equilibrium
... is characterised by fast and slow
developments as a result of interacting
processes
... involves innovation in an important part
of a societal subsystem
(Kemp and Rotmans, 2001)

\footnotetext{
2 The KSI-network comprises about 70 researchers with specific knowledge and expertise of transitions and system innovations. These are not people with domain-specific knowledge, such as energy, agriculture, transport, or space utilization. Their knowledge is more in the sense of transition process architecture, system knowledge of transition, competence, learning processes in transitions, competence development in transitions, and instruments for initiating, guiding, monitoring, and evaluating transitions.
} 
change when things reinforce each other, which again is followed by slow change in the new equilibrium ${ }^{3}$. The underlying mechanism is that of co-evolution, because different subsystems co-evolve with each other, leading to irreversible patterns of change. There are multiple shapes a transition can take but the common shape is that of a sigmoid curve such as that of a logistic at the most aggregated level. For example, population size followed an S-curve in the demographic transition. A transition can be accelerated by one-time events, such as a war or large accident (e.g. Chernobyl) or a crisis (such as the oil crisis) but cannot be caused by such events. That is due to the co-evolution of a set of slow changes, which determine the undercurrent for a fundamental change. Superimposed on this undercurrent are events such as calamities, which may accelerate the transformation process.

Although each transition is unique in terms of content and context, we may distinguish between two types of transitions (Kemp and Rotmans, 2004):

- Evolutionary transitions, in which the outcome is not planned in a significant way;

- Goal-oriented (teleological) transitions, in which (diffuse) goals or visions of the end state are guiding public actors and orienting the strategic decisions of private actors.

With this preliminary typology we do not pretend to capture all forms of transition, but try to indicate that transitions differ by nature, scope and driving forces. An example of an evolutionary transition is the transition from sailing ships to steam boats (Geels, 2002), while an example of a goal-oriented transition could be the transition in water management in the Netherlands, which we will elaborate on in section 3 (Van der Brugge et al., 2004).

A second shared KSI-concept concerns a transition framework. This framework can serve as a bridge between the different disciplines studying partial aspects of transitions and system innovations. We use a preliminary framework, which consists of two transition concepts: the multi-phase and multi-level concepts (Rotmans et al., 2000; Geels and Kemp, 2000). The multi-phase concept indicates that transition paths are highly non-linear with different phases, shifting from one dynamic equilibrium to another. In general, we presuppose that a transition takes place through the following stages (Figure 1):

1. A pre-development phase where there is very little visible change at the systems-level but a great deal of experimentation at the individual level;

2. A take-off phase where the process of change starts to build up and the state of the system begins to shift because of different reinforcing innovations or surprises;

3 This pattern of change seems to coincide with the four phases in the development of ecological systems that Gunderson and Holling discern (2001) 
3. An acceleration phase in which structural changes occur in a visible way through an accumulation and implementation of socio-cultural, economic, ecological and institutional changes;

4. A stabilization phase where the speed of societal change decreases and a new dynamic equilibrium is reached.

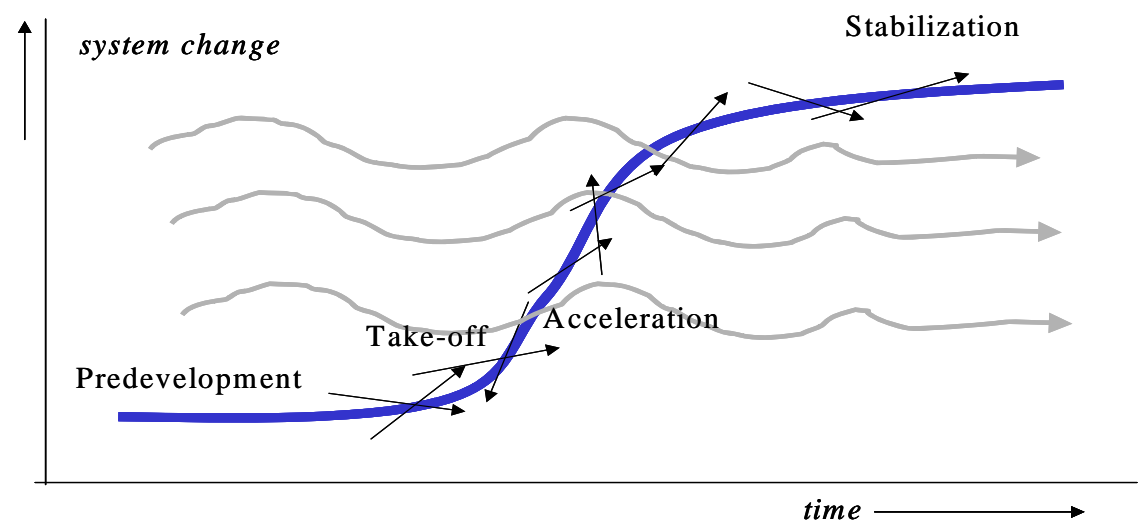

Figure 1: Different stages of a transition at different system levels (Rotmans et al., 2000)

The multi-level concept describes a transition in terms of different scale dynamics, which are interlinked (Geels and Kemp, 2000, Rip and Kemp, 1998). The multi-level concept makes a distinction between niches, regimes and the socio-technical landscape at three interacting scale levels: the micro-, meso- and macro-level. At the macro-level the societal landscape is determined by slow changes in society. Operating at the meso-level are the social norms, interests, rules and belief systems that underlie companies', organisations' and institutions' strategies and political institutions' policies. Acting the micro-level (niche-level) are individual actors, technologies and local practices. At this level, variations to and deviations from the status quo can occur as a result of new ideas and new initiatives such as new techniques, alternative technologies and different social practices.

The third shared concept is that of transition management (to which we will return in section 4), which is rooted in fields such as multi-level governance and adaptive management (Rotmans et al., 2000). This concept indicates that, although transitions cannot be managed in terms of command and control, they can be managed in terms of influencing and adjusting: a more subtle, evolutionary way of steering. In other words, the direction and pace of transitions can be influenced even if not controlled directly. Transition management therefore aims to better organise and coordinate transition processes at a societal level and tries to steer these in a sustainable direction.

Based on the above-described shared research concepts, the following objectives have been derived as specified by KSI (Rotmans et al., 2003).

- To further develop the theoretical concepts for describing and explaining transitions to sustainability and empirically testing these theoretical axioms 
- To develop a new governance concept that reflects the principles of transition management and to test the principles underlying this new paradigm by applying them in practical transition experiments;

- To further develop existing practical tools and instruments and develop new tools and instruments to adequately initiate, stimulate, support, monitor, effectuate and evaluate transitions and system innovations.

The complex systems approach is central to this research program (e.g. Midgley, Bertalanffy et al., Holland). Not as a straightjacket, however, but as an over-arching way of thinking within which other research approaches can fit. The rationale for taking the complex systems approach as an umbrella for studying current and future transitions and system innovations is threefold: (i) the transition domains of our research foci could be considered as complex systems themselves; (ii) the close and recursive relation between transitions and system innovations, which makes the complex systems approach an obvious choice; and (iii) as a unifying principle the complex systems approach offers a framework for synthesizing different knowledge strands which is necessary for addressing transitions and system innovations.

\section{The Water transition}

A good example of the dynamics of transitions, as well as of how the multi-phase and multi-level approach can serve to analyse transitions, is the transition that occurred in Dutch water management over the last decades. This example is interesting, particularly because it resembles not so much an example of a shift in technological regime, but rather a shift in management style and institutional regime.

For an extensive description of this transition case we refer to Van der Brugge et al. (2004). Since the 1970s, a shift from a technocratic water management style to the current practice of integrative and participatory water management took place. The construction of the famous Delta Works in retrospect seems to haven been an important turning point in the shift from the old to the new water perspective. This prestigious water defence project in the Dutch province of Zeeland had profound consequences for the surrounding nature and its ecological functions. The planning process for the construction of the Eastern Scheldt storm surge barrier (one of the Delta Works) started in the mid-sixties. It was a time of growing attention towards environmental issues both at the local and at the global level; the vulnerability of nature due to human interventions was becoming clearer (changing the macrolandscape).

Furthermore, the direct ecological consequences of the Delta Works were so profound that ecosystems were destroyed or changed. The protests against the Eastern Scheldt storm barrier slowly found their way to national debates, gradually increasing the pressure on the water management regime. This was reflected in reports such as 'Dealing With Water' (RIZA, 1985), which articulated for the first time some of the problems concerned with the then current water-management style. In that same period the first building blocks for integrated water management came from niches outside the water regime. In 1987, six people from the Dutch ministry of Agriculture, 


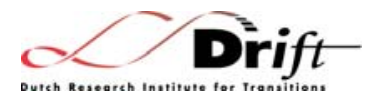

Nature and Fishery (LNV) and Rijkswaterstaat (the leading Dutch water management institution) won the national Eo Wijers 'Netherlands - Riverland' contest about the future of Dutch water management, with a plan called 'Plan Ooievaar'. From an environmental point of view, the plan contained original and innovative ideas with regard to future water management.

At the end of the eighties, an obvious change in water management was going on. The third national memorandum on water management (Rijkswaterstaat, 1989) built upon the vision presented in Dealing With Water' and 'Ooievaar' (Bruin et al., 1987). In the memorandum, the water regime actors expressed their interest in the integrated water management concept. However, the resistance from regime actors against the approach was immense. The district water boards for instance promptly took the position that this strategy could not be realised and was infeasible. These boards were traditionally split up into small-scale quantity water board units and large-scale quality water board units. Their opposition was not surprising however, because as a consequence of implementing the integrated water management concept presented in the memorandum, first steps were taken to reorganize and reorient these district water boards.

The emergence of the new perspective coincided with gradual destruction of the old regime, which characterises the predevelopment-phase. During the 1980s and 1990s Dutch policy promoted the decentralization of government and stimulated privatisation and liberalisation. In general, the decentralization trend in the Netherlands also had its effect on water management and its institutions. More and more work had to be done by parties other than Rijkswaterstaat and regional directories were becoming more independent from the central government. On the one hand, this resulted in a decreasing number of staff within Rijkswaterstaat. On the other hand, the focus on ecological consequences required other competencies and new professions in the hierarchical regime of water engineers. The slow depletion of the old regime paved the way for water management to become a more multidisciplinary and less hierarchically managed regime.

In the nineties, large-scale calamities (i.e. river floods and near disastrous high river discharges) created momentum for the further implementation of the new water strategy. The floods brought water management back on the political agenda. But there still is a considerable gap between the conceptual and theoretical notions behind the new water management and the actual practice. Water management should be based on principles of uncertainty, anticipation and participation and the whole of water management should be more adaptive to rapidly changing external forces.

In sum, from a multi-phase perspective the pre-development phase of the water transition had already started in the sixties with the construction of the Eastern Scheldt storm surge barrier. The shift from the pre-development phase to the take-off phase took place around 1995, after the second major flood. By then the new perspective had become strong and consistent enough, but this convergence had particular consequences for water management. In 2004 the integrated vision on water management, nature development and spatial planning is broadly supported and disseminated by many water managers, spatial planners and nature preservers. 
Implementation of this new water vision is now taking shape in the water regime at the meso level, indicating that the transition is somewhere close to the acceleration phase (Van der Brugge et al., 2004).

Analyzing this transition from the multi-level perspective shows that the initiatives and developments at the micro-level (ecological concerns, spatial planning issues, individual innovators) were gelling with changes at the landscape level (in terms of growing ecological awareness and climate change) in such a way that the predominantly technocratic water management regime could be influenced by innovators and innovations. Currently, these different developments are modulating and reinforcing each other, leading to structural changes in institutions as well as physical infrastructures. In our analysis, this means that the transition is in the takeoff stage, nearing the acceleration stage. But while this change is obviously taking place, the transition could easily get locked-in' because of the problems that arise while implementing large-scale transition plans. The most important aspect in this regard is to co-ordinate experiments in such a manner that they contribute to systeminnovation towards a more sustainable regime. Various experiments have been set out in the field of integrated water management, but without overall coordination of these experiments or a unifying transition direction. What is now needed seems to be an overall approach that takes into account the mentioned complexities and uncertainties but at the same time allows for experiment and innovation. The question of course is whether such a process can indeed be managed or steered in a desired direction.

\section{Possibilities for managing transitions}

\subsection{Introduction}

What are the possibilities for managing transitions? Can transitions be managed? The simple answer to these questions is that transitions cannot be managed in the traditional sense. The reason is that transitions are the result of the interplay of many unlike processes, several of which are beyond the scope of management, such as cultural change, which can be considered an autonomous process. What one can do, however, is influence the direction and speed of a transition through various types of steering and coordination. Thus, transitions defy control but they can be influenced. The management of transitions can be done through the (direct and indirect) use of three co-ordination mechanisms: markets, plans and institutions ${ }^{4}$. Transition management uses markets by relying on price mechanisms and decentralized decision making for making product and service choices. It makes use of planning in the form of transition goals, policy strategies and objectives that centrally coordinate economic activities. Institutional coordination, the third type of co-ordination, consists of new models for policy, the development of transition arenas, agendas and goals, the fostering of new networks and a focus on learning processes. In transition

\footnotetext{
${ }^{4}$ We use the terms institutions to refer to organizations and regulation as well as to 'soft' institutions such as behaviour and routines.
} 


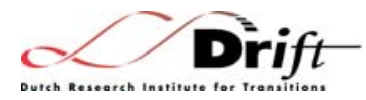

management, transition arenas play a crucial role. Transition arenas are networks of innovators and visionaries that develop long term visions and images that, in turn, are the basis for the development of transition-agendas and transition-experiments, involving growing numbers of actors.

In this section we offer a conceptual as well as a practical model for managing transitions to sustainability. The conceptual model has been developed and used for the 4th National Environmental Policy plan of the Netherlands (NMP-4). Transition management consists of a deliberate attempt to stimulate a transition towards a more sustainable future. There are different ways of trying to achieve a transition. One can opt for the use of economic incentives, rely on a planning and implementation approach or use a combination in the form of market-based planning derived from institutional strategies and sustainability visions.

The basic steering philosophy underlying transition management is that of anticipation and adaptation, starting from a macro-vision on sustainability, building upon bottom-up (micro) initiatives, meanwhile influencing the meso-regime. Goals are chosen (often implicitly through debates and opinions) by society and the systems designed to fulfil these goals are accordingly created through a bottom up approach using adaptive policies. The policies designed to further the goals are not set into stone but are constantly assessed and periodically adjusted in development rounds (Teisman, 2000). Existing and possible policy actions are evaluated against two criteria: first, the immediate contribution to policy goals (for example in terms of kilotons of $\mathrm{CO}_{2}$ reduction and reduced vulnerability through climate change adaptation measures), and second, the contribution of the policies to the overall transition process. A schematic view of transition management is given in figure 2 .
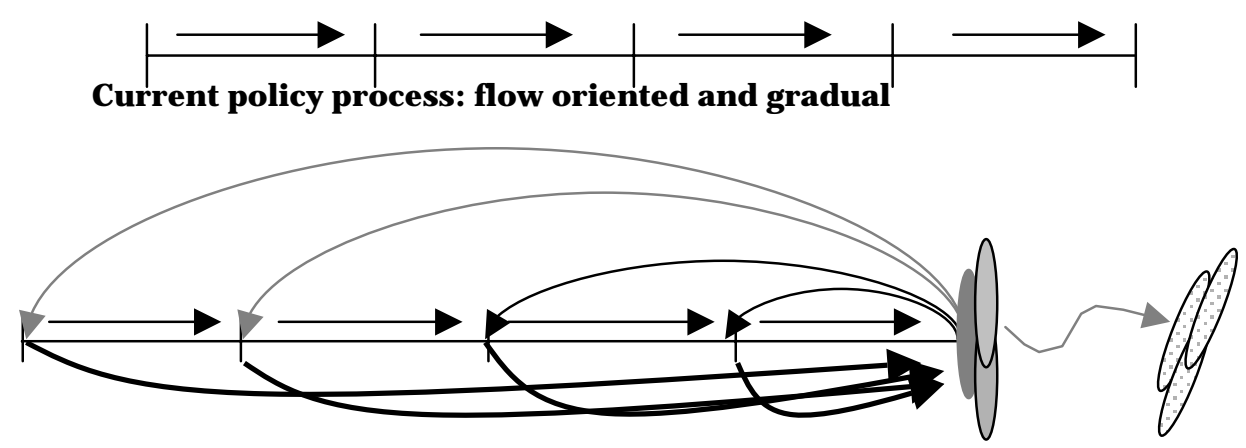

Transition management: oriented towards long-term sustainability goals (plurifocal)

Figure 2: Current policy process versus transition management process

Transition management is based on a two-pronged strategy. It is oriented towards both system improvement (improvement of an existing trajectory) and system innovation (representing a new trajectory of development or transformation). The role of government varies per transition phase. For example, in the predevelopment stages there is a need for social experimentation and creating support for a transition programme, the details of which should evolve with experience. In the acceleration phase there is a special need for controlling the side effects of large-scale applications of new technologies.

Transition management breaks with the old planning-and-implementation model aimed at achieving particular outcomes. It is based on a different, more process- 
oriented and goal-seeking philosophy which helps to deal with complexity and uncertainty in a constructive way. As such, transition management also breaks with the famous Dutch consensus based polder-model by opting for consensus on longterm sustainability goals, while at the same time allowing for diversity and informed dissent in the short term.

Key elements of transition management are:

- Systems-thinking in terms of more than one domain (multi-domain) and different actors (multi-actor) at different scale levels (multi-level); analysing how developments in one domain or level gel with developments in other domains or levels; trying to change the strategic orientation of regime actors;

- Long-term thinking (at least 25 years) as a framework for shaping short term policy;

- Back- and fore-casting: the setting of short-term and longer term goals based on long-term sustainability visions, scenario-studies, trend-analyses and short-term possibilities;

- A focus on learning and the use of a special learning philosophy of learningby-doing and doing-by-learning;

- An orientation towards system innovation and experimentation;

- Learning about a variety of options (which requires a wide playing field);

- Participation from and interaction between stakeholders.

\subsection{The transition management cycle}

Transition management conceptually can be described as a cyclical and iterative process. To make the conceptual model of transition management as outlined above operational, transition management could be organised in so-called development rounds. In this section we will present a model to make transition management operational, which is being tested at various (governmental) levels ${ }^{5}$. One round consists of four main activities: establishing and further developing a transition arena for a specific transition theme; the development of a long-term vision for sustainable development and a common transition agenda; the initiation and execution of transition-experiments; and the monitoring and evaluation of the transition process. Those four activities are (cyclically) represented in Figure 3. Based on the experiences now available, one transition cycle is estimated to take about two to five years, depending on the practical context within which one has to operate.

\footnotetext{
${ }^{5}$ In the Netherlands, the model has been adopted by five different ministries, who are trying to implement it, see for example: www.energietransitie.nl .
} 


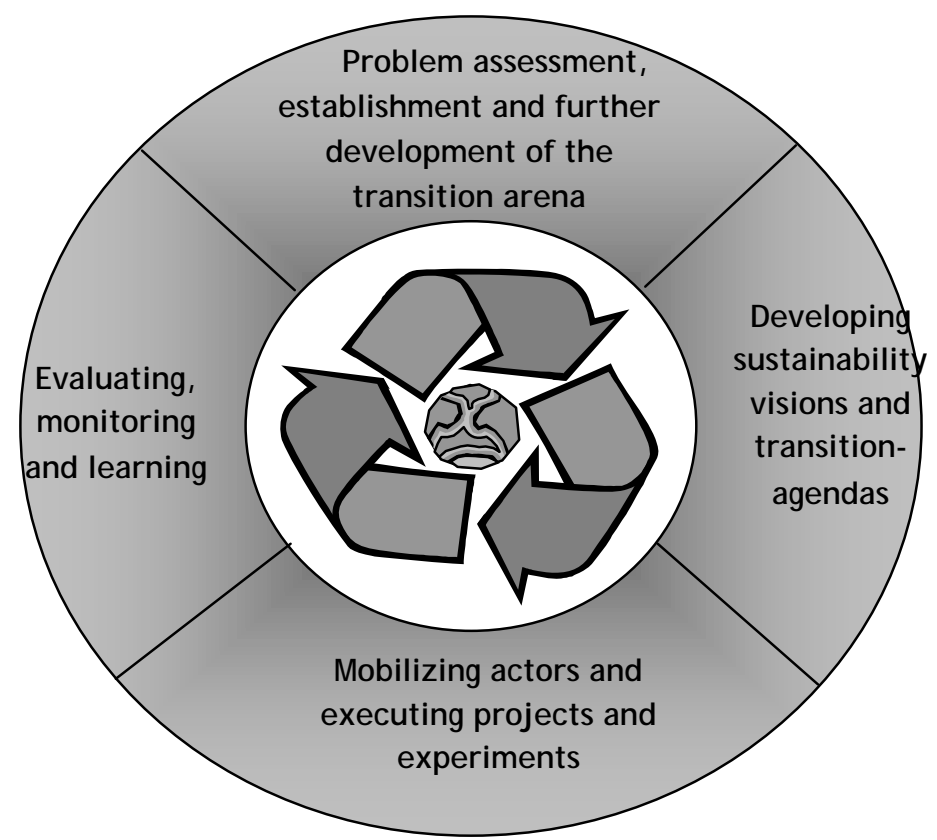

Figure 3: Activity clusters in transition management

The establishment, organisation and development of a transition-arena

The establishment and organisation of a transition-arena forms the basis of the transition management process. The selection of participants for the transition arena is of vital importance; they need to reflect the complexity of the transition at hand. Participants need to have some basic competencies at their disposal: they need to be visionaries, forerunners, able to look beyond their own domain or working area and be open-minded. They must function quite autonomously within their organisation but also have the ability to convey the developed vision(s) and develop it within their organisation. Apart from this, they need to be willing to invest a substantial amount of time and energy into playing an active role in the transition-arena process. It is important to specify explicitly the criteria with which the participants of the transition-arena are selected and to document these criteria.

Another important element is the facilitation of the transition-arena. Not only facilitation in process terms but also in terms of substance. A continuous process of feeding the participants in the arena with background information and detailed knowledge on a particular topic is necessary to enable a process of co-production of knowledge among the participants. This is of vital importance because arenaexperiences show that in most cases arena-participants have insufficient time, lack specific knowledge or don't have enough perspective with which to deepen their understanding of the often complex problems. Therefore they must be fed with substantive knowledge, just as the knowledge developers must be fed in turn with (tacit) knowledge from the arena-participants. This substantive support concerns issues such as framing of the transition issue in time and space and in relation with other issues in other relevant fields, the development of a shared problem perception (what is the deeper problem we perceive?) and the sense of urgency that may or may not be shared.

There is an important role here for the transition manager, who brings together the various parties, is responsible for the overall communication in the transition-arena, 


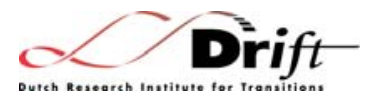

acts as intermediary in discordant situations and has an overview of all the activities in the arena. The transition manager should also ensure a balanced representation of participants from business, governments, non-governmental organisations, knowledge institutions and end-users/consumers. After some time arenaparticipants may be replaced by new participants with other competencies and practical orientations. The transition manager guards this substitution process carefully in order not to disturb the balance in the arena.

\section{The development of sustainability visions and a transition agenda}

Organising an envisioning process for sustainable development is a difficult task. It requires questioning one's own paradigm and leaving aside the concomitant everyday noise. It also requires insight and imagination to look ahead one or two generations. Last but not least it requires agreement among often diverging opinions on what sustainability means for a specific transition theme. Many sustainability visions are still imposed by the government upon other parties in a top-down matter or originate from a select group of experts who are far from representative of the broad social setting.

The long-term visions of sustainability can function as a guide for formulating programmes and policies and setting short-term and long-term objectives. These visions must be appealing and imaginative so as to be supported by a broad range of actors. Inspiring final visions are useful for mobilising social actors, although they should also be realistic about innovation levels within the functional subsystem in question.

The inspiring, imaginative and innovative transition visions are represented by transition images. Rather than considering transition images as optimal societal blueprints, we consider transition images as integral target images, which evolve over time and depend on new insights and learning effects. The transition images embrace transition goals, which are qualitative rather than quantitative, multi-dimensional, and should not be defined in a narrowly technological sense, but should represent the three dimensions of sustainability: economic, ecological and socio-cultural. Ideally the images should be democratically chosen and based on integrated risk analysis, but this does not imply a consensus on these goals since a number of (even contradicting) images and goals can be chosen. This way multiple transition visions, represented by multiple transition images, are developed, creating a basket of images as represented in Figure 4. The fact that sustainability is an essentially contested notion is thus addressed by allowing for diversity in the short-term while trying to achieve consensus on long-term ambitions. In real life, a number of possible interpretations, expectations and visions related to the future will be present, making it impossible to reach a short-term consensus.

Various transition pathways lead to a particular transition image, and from various transition images a particular transition pathway may be derived. The transition images can be adjusted as a result of what has been learned by the players in the various transition experiments. The participatory transition process is thus a goalseeking process, where the transition visions and images, as well as the underlying 
goals change over time. This differs from so-called 'blueprint' thinking, which

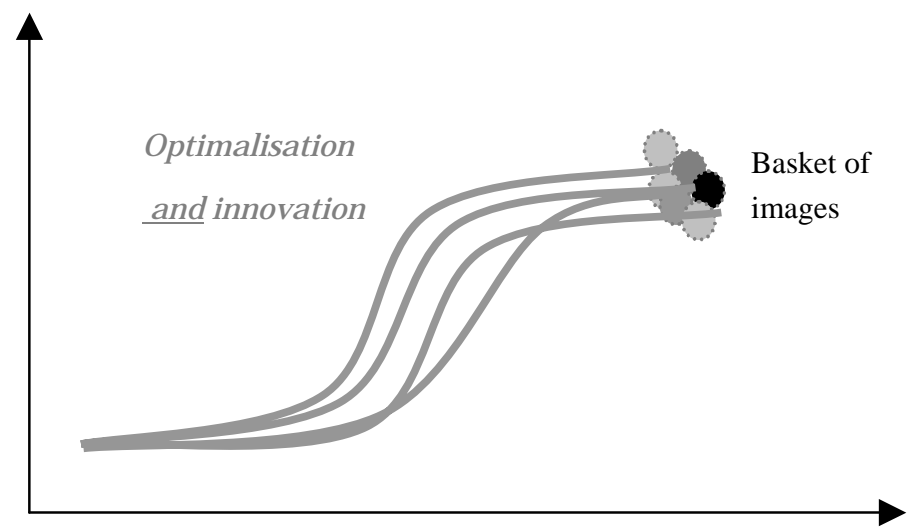

Figure 4: Transition process as a goal-seeking process

operates from a fixed notion of final goals and corresponding visions.

Based on a process of variation and selection, new visions and images emerge, others die out and existing ones will be adjusted. Only during the course of the transition process will the most innovative, promising and feasible transition visions and images be chosen. This evolutionary goal-seeking process means a radical break with current practice in environmental policy where quantitative standards are set on the basis of studies of social risk, and adjusted for political expediency. Risk-based target setting is doomed to fail when many issues are at stake and when the associated risks cannot easily be expressed in fixed, purely quantitative objectives.

Figure 3 shows the similarities and differences between current policy-making and transition management. In each case, interim objectives are used. However, in transition management these are derived from the long-term objectives (through back-casting'), and contain qualitative as well as semi-quantitative goals and measures. In other words, the interim transition objectives contain content objectives (which at the start can look like the current policy objectives, but later will look increasingly different), process objectives (speed and quality of the transition process) and learning objectives (what has been learned from the experiments, what is blocking progress, identification of things that we want to know).

Based on the common problem perception and the shared sustainability vision(s), a joint transition-agenda can be designed. This is important because all arenaparticipants take their own agenda into the transition-arena, whereas a joint transition-agenda contains common problem perceptions, goals, action points, projects and instruments. The means for effectively executing the proposed plans are important in order to resolve the problems on the transition-agenda as adequately as possible. A transition-agenda is actually a joint action programme for initiating or furthering transitions. It is important to set down which party is responsible for which type of activity, project or instrument to be developed or applied. The monitoring of this joint action programme is important in order to guarantee that the transition-agenda is complied with as closely as possible. Instruments are used here in the broad sense: from tax measures to public-private arrangements, but also new 


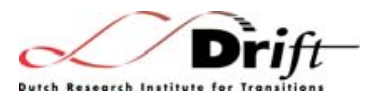

instruments, for example systemic instruments (Smits and Kuhlmann, 2002). The transition-agenda forms the compass, which the transition-arena participants can follow during their transition journey.

An insufficiently robust and ill-supported transition-agenda creates a serious barrier for transition management. If the transition manager under invests in the quality of the transition-agenda, many problems remain below the surface, which will arise later in the transition process. An adequate transition-agenda, however, can form a binding element in the transition process. The transition-agenda requires a balance between structure and flexibility. Structure is needed to position the scale levels in which the issue in question plays, and to frame the issue in terms of themes and sub themes. The coherence between the various sub themes and scale levels is a separate and important point on the transition-agenda. Structuring the transition-agenda is time-consuming but pays-off in the form of increased quality of the transition management process (Dirven, Rotmans and Verkaik, 2002). On the other hand flexibility is needed because the transition-agenda is dynamic and changes over time. In the longer term, themes, goals, means and instruments change, and so the transition-agenda evolves. Practically, the transition-agenda forms the long-term context for short-term policy, within which the current policy fits. If this does not match, the short-term agenda needs to be adjusted. This is an iterative, cyclical and learning process.

\section{The initiation and execution of transition-experiments}

From the transition visions and images, transition-experiments are derived. The transition-experiments are supposed to contribute to the sustainability goals at the system level and should fit within the transition pathways. It is important to formulate sound criteria for the selection of experiments and to make the experiments mutually coherent. The crucial point is to measure to what extent the experiments and projects contribute to the overall system sustainability goals and to measure in what way a particular experiment reinforces another experiment. Are there specific niches for experiments that can be identified? What is the attitude of the current regime towards these niche experiments? The aim is to create a portfolio of transition-experiments, which reinforce each other and contribute to the sustainability objectives in significant and measurable ways.

Preferably, these experiments should link up with ongoing innovation projects and experiments in such a way that they complement each other. Often, many experiments exist, but are not set up and executed in a systematic manner, resulting in a lack of cohesion. Because transition-experiments are often costly and timeconsuming, the existing infrastructure for innovation experiments should be used as much as possible. A lack of cohesion puts constraints on the feasibility and running time of experiments. The execution of experiments should be done through the existing networks of arena-participants to ensure the direct involvement of these forerunners within participating organisations.

Transition processes are beset with structural uncertainties of different kinds. It is therefore important to keep a number of options open and to explore the nature of these uncertainties in the transition-experiments in order to determine which 


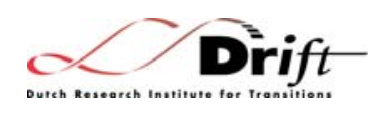

uncertainties are structural and which ones can be reduced. Uncertainties can be the result of a lack of knowledge and may thus be reduced, but they can also be caused by the variability of the system and so are structural and irreducible by nature. In the transition management cycle these uncertainties need to be explored and mapped in a systematic manner. Through learning with transition-experiences the estimation of these uncertainties changes in the course of the transition process. This in turn may lead to adjustment of the transition visions, images and goals. In this search and learning process, scenarios play an important role, in particular explorative scenarios, which attempt to explore future possibilities without too many decision-making constraints (Van Notten et al., 2003).

\section{Monitoring and evaluating the transition process}

Continuous monitoring is a vital part of the search and learning process of transitions. We distinguish between two different processes to be monitored: the monitoring of the transition processes itself and the monitoring of transition management. Monitoring the transition process itself has to take place at different levels in terms of monitoring the slowly changing macro-developments, the sharply fluctuating niche-developments as well as the individual and collective actors at the regime level. This provides the 'enriched context' for transition management. The monitoring of transition management requires a different form of monitoring. First the actors within the transition arena must be monitored with regard to their behaviour, networking activities, alliance forming and responsibilities and also to their activities, projects and instruments. Next, the transition agenda must be monitored with regards to the actions, goals, projects and instruments that have been agreed upon. Finally the transition process itself must be monitored with regards to the rate of progress, the barriers and points to be improved, etc.

Learning-by-doing and doing-by-learning is the essence of transition management. Learning-by-doing concerns the development of theoretical knowledge from practice, whereas doing-by-learning is the development of practical knowledge from theory. Monitoring these learning processes, however, is easier said than done. There is hardly any experience with monitoring and documenting this kind of learning processes. The phenomenon of '(social) learning' is for many still an abstract notion that cannot be easily translated into components for monitoring. It is therefore important to formulate explicit learning goals for transition experiments, which can be monitored.

The evaluation of the above learning processes is in itself a learning process, and may lead to adjustment of the developed transition vision(s), transition-agenda and the transition management process within the transition-arena. The set of interim objectives are evaluated to see whether they have been achieved; if this is not the case, they are analysed to see why not. Have there been any unexpected social developments or external factors that were not taken into account? Have the actors involved not complied with the agreements that were made? Once these questions have been answered a new transition management cycle starts which takes another few years. In the second round of this innovation network the proliferation of the acquired knowledge and insights is central. This requires a specific strategy for initiating a broad learning process. 


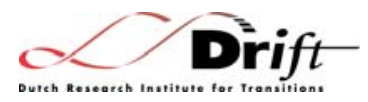

Because these transition management cycles take several years within a long-term context of 25-50 years, the creation and maintenance of public support is a continuous concern. When quick results do not materialise and setbacks are encountered, it is important to keep the transition process going and to avoid a backlash. One way to achieve this is through participatory decision-making. Societal support can also be created in a bottom-up manner, by bringing in experiences with technologies in areas in which there is local support. The experience may remove broader fears and give proponents a weapon. With time solutions may be found for the problems that limit wider application.

\section{Conclusions}

In this chapter we outlined the models of transitions and transition management for achieving a more sustainable society. We argued that transitions are necessary to achieve more sustainable solutions and that current policies are not sufficient. We need new modes of governance that, more adequately than current governance approaches, deal with the complexity and unstructured nature of 'sustainability' problems and which involve a large variety of stakeholders. To this end we presented the approach of transition management, which is operationalised through transition arenas.

Transition management offers a new policy perspective that uses the power of both markets and planning and is engaged with the establishment of new as well as the change of old institutions. Through transition management, a transition path is not pre-selected but created in the attempt to traverse. By creating a little bit of irreversibility in the right direction, the transition process is pushed forward in a stepwise manner. This approach implies a new role for governments that should thus engage in societal alignment policies-aligning policies and policy goals to visions of sustainability, through transition agendas and the use of process management. This does not render the use of regular policy instruments such as regulation and pricing mechanisms obsolete, but says that these should be undertaken as part of a broader transitional approach that aims at the anticipation and adaptation of societal dynamics to sustainability goals.

Transition management was adopted as Dutch policy in 2001 when five ministries started developing transition policies for mobility, agriculture, energy-supply and biodiversity. Currently, different transition arenas have been established, visions developed and agendas aligned. Also, a large number of experiments in all these fields have been set out. For the coming years the achievement of real-life successes and a further deepening of the concepts of transitions and transition management will be crucial. In our view, transition management not only makes good sense but is also the only possible (and do-able) way of achieving true sustainability benefits in the long-term while maintaining short-term diversity. The implementation of transition management, however, is dependent on factors such as creativity, perseverance, communication skills and spirit, and its success will therefore depend on those who take up this challenge. 


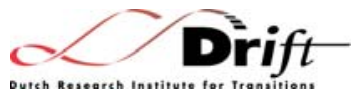

\section{References}

Berkhout, F., Smith, A. and A. Stirling (2003), Socio-technical regimes and transition contexts. SPRU Electronic Working Paper Series, No. 106, University of Sussex, Brighton

Bertalanffy, L. Von, Hempel, C.G., Bass, R.E., Jonas, H. (1951), General Systems Theory: a new approach to the unity of science, Human Biology 23, 302-361

Bruin, D., Hamhuis, D., Nieuwenhuijze, L. van., Overmars, W., Sijmons, D., Vera, F. (1987). Ooievaar: De toekomst van het Rivierengebied. (Ooievaar: the future of the riverland) Arnhem, The Netherlands: Gelderse Milieufederatie.

Dirven, J., Rotmans, J. and Verkaik, A.P. (2002), Society in Transition: an Innovative Viewpoint, Transition Essay, The Hague, The Netherlands

Geels, F.W. (2002), Understanding the Dynamics of Technological Transitions, A co-evolutionary and sociotechnical analysis, $\mathrm{PhD}$ thesis, Enschede: Twente University Press

Geels, F., and Kemp, R. (2000), Transities vanuit sociotechnisch perspectief (Transitions from a socio-technical perspective), background report to the study "Transitions and transition management” by ICIS and MERIT for the NMP-4, November 2000, UT, Enschede en MERIT, Maastricht.

Gunderson, L.H., Holling, C.S. (eds.) (2001), Panarchy: understanding transformations in human and natural systems, Washington, D.C.: Island Press

Holland, J. (1995), Hidden order: how adaptation builds complexity, Reading Mass: Addison-Wesley

Kemp, R., and Rotmans, J. (2001), The Management of the Co-evolution of Technological, Environmental and Social Systems, paper for the conference Towards Environmental Innovation Systems, Eibsee, 27-29 sept, 2001

Kemp, R., and Rotmans, J. (2004), Managing the transition to a sustainable mobility, forthcoming, in Boelie Elzen, Frank Geels and Ken Green (eds.) System Innovation and the Transition to Sustainability: Theory, Evidence and Policy, Cheltenham: Edgar Elgar

Midgley, G. (ed.) (2003), Systems Thinking, Vol. 1-4, London: SAGE Publications

Rijkswaterstaat (1989), Derde nota Waterhuishouding (Third memorandum on Water management), The Haque, The Netherlands.

Rip, A. and Kemp, R. (1998), Technological Change, in Steve Rayner and Liz Malone (eds.) Human Choice and Climate Change, Vol 2 Resources and Technology, Washington D.C.:Battelle Press, 327-399

RIZA, (1985), Omgaan met water (Dealing with water), The Hague, The Netherlands.

Rotmans, J., Kemp, R. van Asselt, M.B.A., Geels, F.W., Verbong, G. and Molendijk, K. (2000), Transitions \& Transition Management: the case of an emission-poor energy supply (in Dutch), Maastricht, the Netherlands: ICIS (International Centre for Integrative Studies)

Rotmans, J., Kemp.R, and van Asselt, M.B.A. (2001), More Evolution than Revolution. Transition Management in Public Policy, Foresight 3 (1), 15-31

Rotmans, J., Grin, J., Schot, J. and Smits, R. (2003), Multi-, inter- and transdisciplinary research program into transitions and system innovations, Maastricht, the Netherlands: ICES-KIS-research program

Smits, R., Kuhlmann, S. (2002), Strengthening Interfaces in Innovation Systems: rationale, concepts and (new) instruments, Report prepared on behalf of the EC STRATA Workshop 'New challenges and new responses for S\&T policies in Europe', Brussels. 22-23 April, 2002

Teisman, G.R. (2000), Models for research into decision-making processes: on processes, phases and decisionmaking rounds, Public Administration 78 (4), 937-956

Van der Brugge, R., Rotmans, J. and Loorbach, D (2004), The Transition in Dutch Water management, Journal of Regional Environmental Change, Springer

Van Notten, P., Rotmans, J., Van Asselt, M. and Rothman, D. (2003), An updated scenario-typology, Futures 35 (5), 423-443

Weaver, P., Jansen, L, Geert, Grootveld and Philip Vergragt (2000), Sustainable Technology Development, Sheffield: Greenleaf Publishing 